This is a post print version. Please refer to the published version: Serafis, D., Greco, S., Pollaroli, C. and Jermini-Martinez Soria, C. (2020). Towards an integrated argumentative approach to multimodal critical discourse analysis: Evidence from the portrayal of refugees and immigrants in Greek newspapers. Critical Discourse Studies 17(5): 545-565

\title{
Towards an integrated argumentative approach to multimodal critical discourse analysis: Evidence from the portrayal of refugees and immigrants in Greek newspapers
}

\author{
Dimitris Serafis ${ }^{{ }^{*}}$ Sara Greco ${ }^{a}$ Chiara Pollaroli ${ }^{a}$ and Chiara Jermini-Martinez Soria ${ }^{a}$ \\ a Institute of Argumentation, Linguistics and Semiotics, Faculty of Communication Sciences, USI - \\ Università della Svizzera italiana, Lugano, Switzerland.
}

\begin{abstract}
This paper proposes a methodological synthesis in order to study multimodal media discourse and argumentation in the context of the so-called 'refugee crisis' in Greece. It follows the framework of Multimodal Critical Discourse Analysis, integrating this with argumentation studies, with a particular emphasis on the analysis of inference. Our data come from the Greek newspapers Kathimerini and Ta Nea. We contend that the proposed methodological synergy enables scrutiny of (a) racist conceptualizations cultivated by the representation of migrants and refugees in headlines and photographs in newspaper articles along with (b) the argumentative potential that is implicitly sustained in these multimodal representations.
\end{abstract}

KEYWORDS: Multimodal Critical Discourse Analysis (MCDA); multimodal argumentation; Argumentum Model of Topics (AMT); print media discourse; Greek newspapers; migration; 'refugee crisis'; Greece

\section{Introduction}

This paper outlines a methodological contribution to the study of multimodal media discourse and argumentation, focusing - as an illustrative example - on Greece during the so-called 'refugee crisis' (see Krżyzanowski, Triandafyllidou \& Wodak, 2018). We provide examples for our proposal by analyzing multimodal configurations contained in headlines and their accompanying photographs in news articles from the Greek newspapers Kathimerini and Ta Nea: two newspapers that carry significant weight in Greek society, representing the mainstream (ideological/political) views circulating in the public sphere (see Psychogios, 2004, p. 477-493). Given the methodological focus of this paper, two representative examples will be used to show the potential of this

\footnotetext{
* Corresponding Author: Institute of Argumentation, Linguistics and Semiotics, Faculty of Communication Sciences, Università della Svizzera italiana. Via Buffi 13, 6900, Lugano, Switzerland.

dimitrios.serafis@usi.ch
} 
This is a post print version. Please refer to the published version: Serafis, D., Greco, S., Pollaroli, C. and Jermini-Martinez Soria, C. (2020). Towards an integrated argumentative approach to multimodal critical discourse analysis: Evidence from the portrayal of refugees and immigrants in Greek newspapers. Critical Discourse Studies 17(5): 545-565

type of analysis; we do not aim to give a full empirical analysis of migrants' and refugees' representations in the media during the selected time period. We follow the framework of Multimodal Critical Discourse Analysis (see e.g. Machin \& Mayr, 2012), integrating it with tools taken from Argumentation theory, in relation to the analysis of inference (see Rigotti \& Greco, 2019). We seek to demonstrate that through this combination, we are better able to unveil (a) racist conceptualizations cultivated via the representation of migrants and refugees in headlines and photographs in (Greek) newspapers, and (b) the argumentative potential that is implicitly established in these multimodal representations.

We speak of argumentative potential, anticipating two possible objections to our claim. The first objection derives from the fact that we examine types of texts (news stories and, especially, the interplay between headlines and images) which do not have a declared argumentative function - at least, not in the sense in which an editorial or an opinion piece might have. Nevertheless, following studies which have already shown that news stories can be the source of argument development (Richardson, 2007; Greco Morasso, 2012), we contend (and will demonstrate) that, if interpreted within their contextual background, these seemingly non-argumentative texts can trigger argumentative inferences. Accordingly, part of the innovation of this paper lies in highlighting how Multimodal Critical Discourse Analysis can be rigorously interwoven with tools from argumentation. To date, multimodal critical discourse studies have extensively examined the ways in which meaning is constructed equally through verbal and visual means in newspaper texts (Kress \& Van Leeuwen 1998; Bednarek \& Caple 2012a; Breazu \& Machin, 2018, to name but few). Argumentation studies have, moreover, shown how verbal and visual interplays can be viewed as developing arguments in favor of a particular standpoint (see e.g. Tseronis, 2015, 2017).

A second objection may arise because we focus specifically on headlines and photos. Specifically analyzing the headline-photo relation in news articles, Bednarek \& Caple (2012b, Chapter 5 ) provided empirical findings on how these elements cultivate meaning(s). We, moreover, maintain that an argumentative dynamic is implicitly developed in the multimodal construal, which is realized in the headline-photo interaction. As Van Dijk (1988, 1991a, 1991b) claimed, headlines set out newspapers' topic(s) while they 'summarize the text and specify the most important information' (Van Dijk, 1991b, p. 113). They may also sustain the main (ideological/political) claim (Serafis \& Herman, 2018, p. 185; see also Bell, 1991) since they are 'perceived as arguments for an implicit standpoint' (Zampa, 2017, p. 131). The accompanying photographs may amplify the standpoint implicitly contained in headlines since we acknowledge the premise that these 'possess an argumentative potential' (Kjeldsen, 2017, p. 53). We should highlight here that we secure our interpretation of headlines 
This is a post print version. Please refer to the published version: Serafis, D., Greco, S., Pollaroli, C. and Jermini-Martinez Soria, C. (2020). Towards an integrated argumentative approach to multimodal critical discourse analysis: Evidence from the portrayal of refugees and immigrants in Greek newspapers. Critical Discourse Studies 17(5): 545-565

and press photos by also drawing on our broader corpus (including the text of the news articles) as well as on contextual knowledge as sources for our reconstruction. This analytical principle is suggested within the criteria for argumentative reconstruction in Van Eemeren and Grootendorst (2004, p. 112).

Overall, the assumption underpinning this article is that the aforementioned multimodal interplay does not only construe migrants' and refugees' portrayals but also gives rise to contextualized conceptualizations of migrants and refugees that subtly trigger inferences in an argumentative manner, supporting different standpoints (e.g. the prevention of the phenomenon of migration). Consequently, an integrated argumentative approach to Multimodal Critical Discourse Analysis is proposed as a method of reconstructing their argumentative dimensions that would otherwise remain obscure.

In what follows, we present our methodological and analytical considerations, pinpointing the methodological improvement that our proposal suggests. We then move towards our analysis, illustrating the application of our methodological synergy. In the concluding section, we underline the explanatory assets of the proposed approach, simultaneously sketching some tentative conclusions.

\section{Methodological and analytical considerations}

As already indicated, this paper falls within Multimodal Critical Discourse Analysis (MCDA) (see among others Machin \& Mayr, 2012) and combines it with Argumentation theory. MCDA is a scholarly agenda which, acknowledging the predominantly multimodal character of contemporary communication (see Kress, 2010), and drawing on the notions and principles of Critical Discourse Analysis (CDA) (see Flowerdew \& Richardson, 2018), aims to unveil the ways social problems, such as racism and xenophobia, are (re)produced via multimodal texts and discourses. Specifically, Multimodal Critical Discourse Analysis examines how different modes of semiosis (e.g. language and images) co-construct contextualized discourses, favoring and sustaining the socio-political status quo (see Ledin \& Machin, 2018). We use the term discourse to describe the coherent semiotic ways in which the social and cultural world is portrayed (see Fairclough, 2003); a construal that often revolves around a thematic criterion ${ }^{1}$ and is associated with argumentation (see Resigl \& Wodak, 2001).

We employ the principle that examines the interconnection between the macro-level (dominant) values and views and the micro-level of discursive choices, strategies and texts (see Van Dijk, 2008, p. 85-89). Through this bifocal lens, coherent discourses are constructed. In the present case, macro-level refers to the (racist) values 
This is a post print version. Please refer to the published version: Serafis, D., Greco, S., Pollaroli, C. and Jermini-Martinez Soria, C. (2020). Towards an integrated argumentative approach to multimodal critical discourse analysis: Evidence from the portrayal of refugees and immigrants in Greek newspapers. Critical Discourse Studies 17(5): 545-565

and views which portray migrant populations as 'others' - menaces to their host societies (see Van Dijk, 1991a; Richardson, 2004, 2007; Baker et al., 2008; Gabrielatos \& Baker, 2008; Krżyzanowski \& Wodak, 2008; KhosraviNik, 2009, 2010; Richardson \& Wodak, 2009; Musolff, 2015), while micro-level includes the specific multimodal choices appearing in the Greek newspapers Kathimerini and Ta Nea.

For our micro-level analysis, we outline an argumentative perspective that, as we will show, may sharpen the interpretative abilities of Multimodal Critical Discourse Analysis by bringing to the fore the argumentative potential of multimodal constructions used in newspapers. In this sense, our study adopts an interdisciplinary viewpoint where argumentation works along the conceptual lines of Multimodal Critical Discourse Analysis (see Van Leeuwen 2005). More specifically, through the present study we aim to both capitalize on and deepen the ground established by critical discourse studies that have already fruitfully employed argumentation studies (see e.g. Reisigl \& Wodak, 2001; Fairclough \& Fairclough, 2012).

\section{An argumentative integration to multimodal critical discourse studies - The Argumentum Model of Topics (AMT)}

Broadly speaking, our view in this paper on the argumentative potential of seemingly non-argumentative texts is inspired by Amossy's (2010) framework labelled as 'argumentation in discourse'. Based on Perelman \& Olbrechts-Tyteca's (1969 [1958]) New Rhetoric, Amossy (2009a, p. 317) defines 'argumentation [...] as the use of verbal means to ensure [...] consensus on what can be considered reasonable by a group of people, or by what a society would define as a reasonable person'. Moreover, Amossy (2009b) makes a distinction between argumentative cases where the arguer may deliberately try to persuade the addressee [...] as in a debate' and cases where argumentation remains implicit, as for instance when the arguer may 'orient ways of looking at things and interpreting the world without putting forward any thesis [...] as in an information article'. In doing so, Amossy claims that 'discourse is pervaded by a general argumentativity [that is] [i]t always answers some explicit or hidden question or at least suggests a way of looking at the surrounding world' (2009b, p. 254; our emphasis). Correspondingly, all discursive constructions (especially in public and media discourse, see also the introductory section) entail some argumentative potential (argumentativity) in the sense that 'even discourses that [do not] disclose a manifest persuasive purpose have an underlying argumentative dimension' (Amossy, 2009a, p. 315; our emphasis; see also Amossy, 2005). This view is particularly relevant to the analysis of headlines with a prevailingly referential/descriptive function, even if the journalists and/or newspapers are not necessarily aware of the argumentative function 
This is a post print version. Please refer to the published version: Serafis, D., Greco, S., Pollaroli, C. and Jermini-Martinez Soria, C. (2020). Towards an integrated argumentative approach to multimodal critical discourse analysis: Evidence from the portrayal of refugees and immigrants in Greek newspapers. Critical Discourse Studies 17(5): 545-565

that can be elicited from them (see also Herman \& Serafis, forthcoming, for a similar interpretation of the concept of argumentativity in data emerging from the Greek press). If even seemingly non-argumentative discourses contain an implicit argumentative dimension, then it is argumentative analysis tools that are required to highlight opaque aspects that inform and contribute to the emergence of this argumentative potential in genres of discourse. As Amossy (2009b) puts it, 'the analysis of arguments deals with the ways in which an agreement is achieved in discourse in a communicative framework' and thus 'patterns of reasoning must [...] be [both] reconstructed [and] examined in their exact phrasing' (Amossy, 2009b, p. 317). In sum, argumentation emerges in specific communicative contexts such as the so-called 'refugee crisis' in Greece and may permeate patterns of (print media) discourse such as newspapers headlines where prima facie there is no explicit intention to produce an argumentative text. Accordingly, a systematic scrutiny of the context-dependent (multimodal) micro-level is crucial in order to illustrate the argumentative dynamic borne out in these patterns. To that end, we draw on two different integrations taken from argumentation studies.

First, we rely on the perspectives of multimodal argumentation (Groarke, 1996; Kjeldsen, 2015; Tseronis \& Forceville, 2017; Rocci \& Pollaroli, 2018). In these studies, there is an accepted premise that a cross-fertilization of multimodal, discourseanalytical approaches and argumentation should be favored. As maintained, this can give rise to more holistic approaches that will analyze both how multimodal meaning is transformed into arguments and concurrently how argumentation is based on a multimodal meaning construal (see Tseronis, 2015, p. 19 and references therein). Based on these premises, our proposal employs Van Leeuwen's (2008) social semiotic approach for the representation of social agency. This work has been adopted in cases of critical multimodal discourse analysis (Machin \& Mayr, 2012) and thus is particularly relevant in enabling us to scrutinize (multimodal) meaning constructions. Van Leeuwen's (2008) approach elaborates on the seminal work of Kress \& Van Leeuwen (1996) that established rigorous tools for the analysis of multimodal meaning configurations in contemporary communication, mostly following Halliday's (1978) view of language (and semiosis) as the source of meaning potential in a particular socio-cultural context. Additionally, in the first example, we touch upon how the construction of meaning may be enriched through the use of metaphors. ${ }^{2}$ Notably, approaches taken from (multimodal) argumentation have addressed the use of metaphor in various genres (see e.g. Pollaroli \& Rocci, 2015; Feteris et al., 2011). They have done so since metaphors enhance argumentativity while enabling a generic schema, starting from a target domain associated with a source domain, to be 
This is a post print version. Please refer to the published version: Serafis, D., Greco, S., Pollaroli, C. and Jermini-Martinez Soria, C. (2020). Towards an integrated argumentative approach to multimodal critical discourse analysis: Evidence from the portrayal of refugees and immigrants in Greek newspapers. Critical Discourse Studies 17(5): 545-565

activated; in our case the schema of 'an unstoppable threatening entity' that comes from framing migrants as a natural disaster.

Second, we seek to reconstruct the inferential connection that links the main standpoint implicitly present in the headline/photograph combination to the supporting argument(s). To this end, we employ the Argumentum Model of Topics (AMT) (see Rigotti \& Greco, 2019), a theoretical and methodological tool, which enables a rigorous reconstruction of the argumentative inference. According to its main proponents, the Argumentum Model of Topics aims to contribute to contemporary argumentation studies, relying on the tradition of the study of topoi/loci as sources of arguments, initially founded by Aristotle and developed through subsequent Latin, medieval and post-medieval traditions (see Rigotti \& Greco, 2019, pp. 3-56). More specifically, the Argumentum Model of Topics 'illustrate[s] the structure of reasoning that underlies the connection between a standpoint and its supporting arguments' (Rigotti \& Greco Morasso, 2010, p. 490). In doing so, the Argumentum Model of Topics differentiates between two main components that constitute the inferential configuration of each individual argument. This means that each argument is seen as a combination of two different lines of reasoning that intersect: one is based on an abstract principle (locus), while the other anchors the argument to the concrete sociomaterial and cultural (contextual) background of the interlocutors. On the one hand, the procedural-inferential component includes (a) the locus, that is, the ontological relationship (e.g. cause-effect) from which the argument originates and (b) the maxim, which refers to inferential principles that spring from the locus and give rise to specific arguments (e.g. if the cause is present, so is the effect). Normally, different maxims correspond to the same locus. On the other hand, the material-contextual component includes the shared socio-cultural premises that the participants (supposedly) take into consideration. Namely, (a) a reinterpretation of the endoxon of the Aristotelian tradition which refers to the shared opinion(s) accepted by the (majority of the) public in the specific social and/or cultural setting of the discussion, and (b) the datum, which is a premise of a factual nature that, if associated with the endoxon, allows the conclusion that the endoxon is realized in the specific case in point. The intersection of these two components (procedural-inferential and material-contextual) forms a quasi- $Y$ structure that leads to the final conclusion, i.e. the standpoint that is defended ${ }^{3}$ (Rigotti \& Greco, 2019, pp. 208-216). The two arms of the quasi-Y represent the two components and their intersection. The Argumentum Model of Topics has a specific micro-focus, because it analyzes single argumentations (Van Eemeren \& Snoeck Henkemans 2017, pp. 55-56), i.e. a single standpoint-argument coupling. This microfocus makes it particularly suited for use in this case of analyzing the constructions of meaning in headlines/press photos as (multimodal) micro-argumentative moves. 
This is a post print version. Please refer to the published version: Serafis, D., Greco, S., Pollaroli, C. and Jermini-Martinez Soria, C. (2020). Towards an integrated argumentative approach to multimodal critical discourse analysis: Evidence from the portrayal of refugees and immigrants in Greek newspapers. Critical Discourse Studies 17(5): 545-565

The Argumentum Model of Topics has been previously used in the analysis of media productions (Greco Morasso \& Morasso, 2014; Zampa, 2017) and news stories (Greco Morasso, 2012), but it has never been employed through the prism of Multimodal Critical Discourse Analysis; ${ }^{4}$ neither has it been applied to the analysis of newspaper headlines. For the specific focus of this paper, combining the AMT with Amossy's broader viewpoint-that even texts such as news articles have an argumentative potential-is particularly important. This represents an extension of the use of the AMT, which is part of the methodological integration proposed in this paper.

\section{Sharpening the dialogue in critical discourse studies}

As we have already mentioned, approaches within critical discourse studies have made use of argumentation studies and pointed out possible interconnections. In many cases, this interdisciplinary dialogue has had a particular focus on case studies revolving around racism and its cultivation through the exploitation of various argumentative means (Atkin \& Richardson, 2007; Boukala \& Dimitrakopoulou, 2018) including visual elements (Richardson, 2008; Richardson \& Wodak, 2009). In this sense, our study aims to expound on the extensive CDA work that has been undertaken; in particular the work of the Discourse-Historical Approach (DHA) to CDA (see e.g. Wodak, 2001).

Critical discourse analysts have systematically examined argumentative strategies, since they perceive 'argumentativity' as being among the 'constitutive elements of a discourse' (Reisigl \& Wodak 2016, p. 27). From their perspective, argumentative strategies, realized by the use of topos/topoi, stand among the discursive strategies that permeate texts and discourses. ${ }^{5}$ Drawing selectively on different traditions in argumentation theory, the discourse-historical approach defines topos/topoi as "content-related warrants or "conclusion rules" [which] connect the argument(s) with the conclusion, the claim. In this way, they justify the transition from the argument(s) to the conclusion' and 'can always be made explicit as conditional or causal paraphrases such as "if $x$, then $y$ " or " $y$, because $x$ "' (Reisigl \& Wodak, 2016, p. 35). In fact, Reisigl \& Wodak (2001, pp. 75-80) have already presented a list of the main topoi introduced by the discourse-historical approach. In our view, the focus on topos/topoi that is already present in the discourse-historical approach can be strengthened by an approach such as the Argumentum Model of Topics that, starting from the same tradition, emphasizes how topoi (or loci, if we use the Latin translation of this metaphor) activate argumentative inference. Recent developments in the discourse-historical approach to critical discourse studies seem to confirm the need to highlight how topoi work within inference. In particular, Boukala (2016, 2019, Chapter 4) rethinks topos/topoi within the Aristotelian dialectic syllogism and argues that 
This is a post print version. Please refer to the published version: Serafis, D., Greco, S., Pollaroli, C. and Jermini-Martinez Soria, C. (2020). Towards an integrated argumentative approach to multimodal critical discourse analysis: Evidence from the portrayal of refugees and immigrants in Greek newspapers. Critical Discourse Studies 17(5): 545-565

endoxon/endoxa, that is the shared knowledge in a socio-cultural setting, have to be taken into consideration when examining the justification of a standpoint. Moreover, the author argues that the endoxical premises have to be challenged via the presence of topoi during the dialectic syllogism that explicates the final standpoint occurring in a text (Boukala, 2019, p. 96-97).

We argue that, exploiting these same notions as the discourse-historical approach to critical discourse studies, the quasi-Y reconstruction provided by the Argumentum Model of Topics may deepen and explicate the reciprocal influence of material-contextual and procedural-inferential premises in the justification of a claim; above all in cases such as the one with which we are concerned, where much of the argumentative dimensions and dynamic remain implicit. In this sense, being a tool explicitly developed to study argumentative inference, the Argumentum Model of Topics may sharpen a CDA perspective, as it allows light to be shed on the inferential dynamics that connect abstract principles such as topoi (loci) to shared knowledge in a socio-cultural setting. We will return to this discussion in detail in the concluding section, in the light of our analysis.

\section{Data analysis}

Based on the aforementioned premises, this section elaborates on two examples that explicate the effectiveness of our methodological proposal, which is the primary goal of this paper. We briefly summarize the content of each article at the beginning of each analysis, in order to provide readers with part of the broader information we use to reconstruct implicit materials in the argumentation (notably, standpoints). Then we proceed to a separate analysis of the two distinct elements that form the multimodal configurations (headline-image) before moving towards the reconstruction of the path leading from argument to standpoint. As already mentioned in the previous section, the content of the article (along with the context of situation) is taken into consideration when reconstructing the argumentative dynamic of the interplay between headline and image. In general, any argumentative analysis of discourses in which a significant part of the meaning is implicit, needs to rely on the analysts' interpretation of the text and context (see, in a different context, Greco et al., 2018) and is potentially subject to alternative hypotheses (see the concluding section).

The first article (Kathimerini) reports that the Greek coastguard has located a large number of migrants in the last 48 hours in the Eastern Aegean who lack travel documents. The journalist underlines that this is only a small percentage of the migrants that have been located in total, including in the interior of some of the Greek islands, presenting a view of a rise of migratory inflows that cause more problems to a crisis-ridden country such as Greece. The article concludes with a description of the rescue efforts made by the two national 
This is a post print version. Please refer to the published version: Serafis, D., Greco, S., Pollaroli, C. and Jermini-Martinez Soria, C. (2020). Towards an integrated argumentative approach to multimodal critical discourse analysis: Evidence from the portrayal of refugees and immigrants in Greek newspapers. Critical Discourse Studies 17(5): 545-565

(Greek/Turkish) coastguards between the Greek and Turkish territorial waters. In particular, it describes the number of corpses found, and those who have been rescued as well as those individuals still missing, underlining the difficulties in the rescue operations. ${ }^{6}$

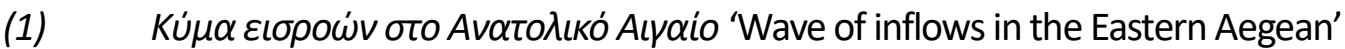

(Kathimerini, 10.07.2015)

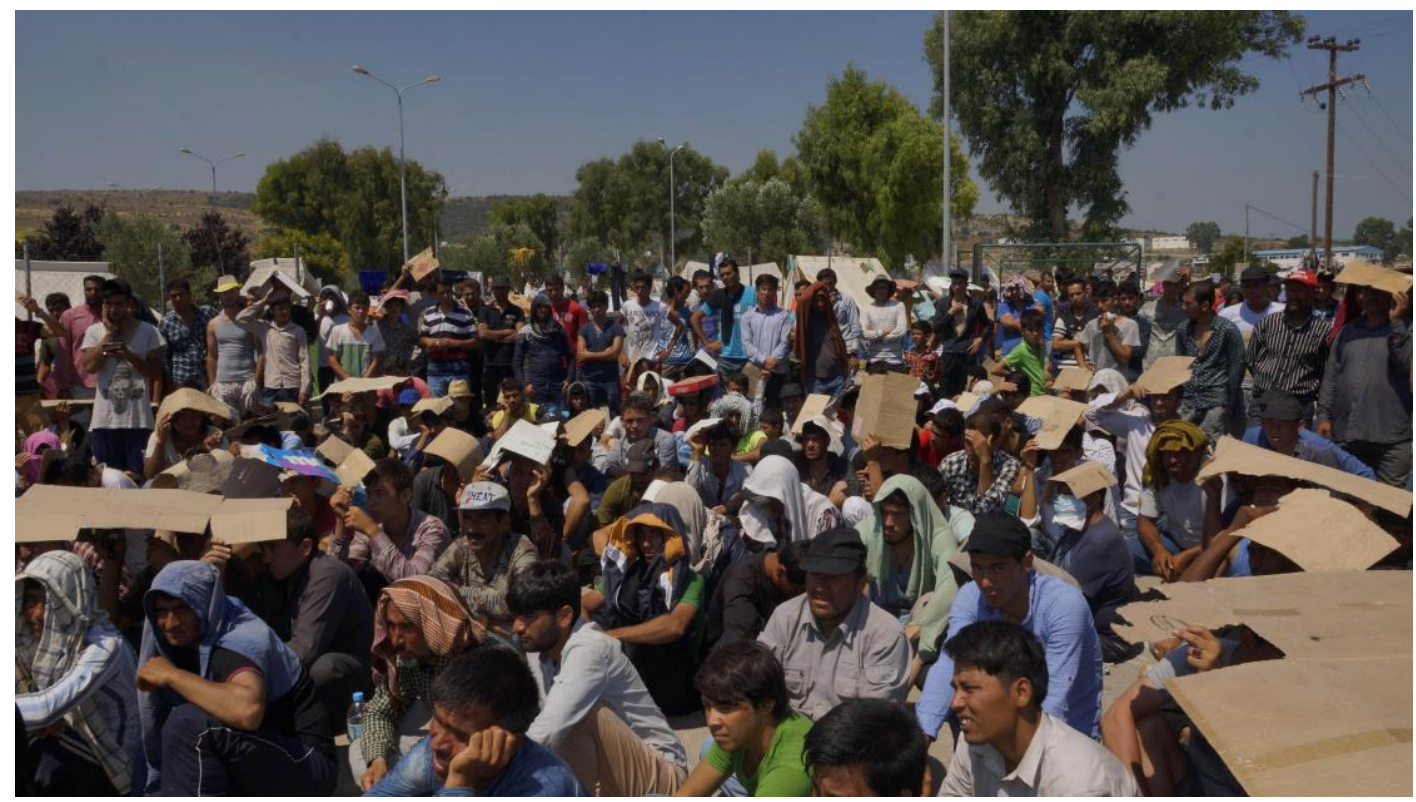

Please insert figure 1 here

Figure 1. Kathimerini, 10.07.2015. With permission: No 1 C ANA-MPA/STRATIS BALASKAS

In headline (1), the representation of migrant populations is realized by the nominal

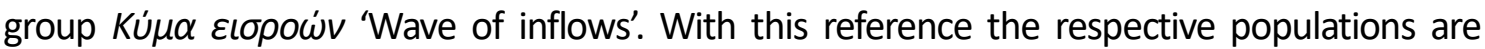
represented as 'impersonalized' and, more specifically, as 'objectivized'; as Van Leeuwen (2008) notes, this form of representation occurs when social actors are related semantically 'with the action in which they are represented as being engaged' (2008, p. 46). Specifically, in our

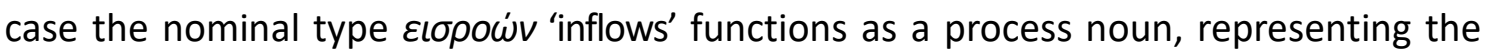
action in which the (impersonalized/objectivized) migrant populations are portrayed as being engaged.

Significantly, the nominal group 'Wave of inflows' realizes a 'dehumanizing metaphor' which is extensively observed in the negative representations of migrant populations in the media, emphasizing their negative characterization as a natural disaster (see e.g. Musolff, 2015). Furthermore, as Martínez-Lirola (2017) points out, the choice of the nominal type 'wave' is a common (metaphorical) choice employed in the 
This is a post print version. Please refer to the published version: Serafis, D., Greco, S., Pollaroli, C. and Jermini-Martinez Soria, C. (2020). Towards an integrated argumentative approach to multimodal critical discourse analysis: Evidence from the portrayal of refugees and immigrants in Greek newspapers. Critical Discourse Studies 17(5): 545-565

representation of migrant populations and it 'adds to portraying an imaginary invasion that makes the [majority] population feel threatened by the[ir] arrival' (2017, p. 422). Migrants are represented as frightening the majoritarian population with a great volume (as in a natural disaster) flowing into the host country. We should also mention here that, as a result of this impersonalization and objectivization, the headline 'does not tell the reader who is responsible for the action' (Van Leeuwen, 2008, p. 47), i.e. who is responsible for the 'Wave of inflows'. In this sense, Kathimerini not only leaves in the background any possible responsibilities of e.g. EU member-states in respect of the acceleration of conflicts and wars in migrants' and refugees' places of origin, but also decisively and effectively attributes the blame for a massive influx-disaster to the migrant populations. This very fact facilitates the newspaper's choice in this context to shift the discussion towards the issue of: 'how will we stop this massive influx'?

Overall, the represented actors are conceptualized as a threatening mass something 'other' (analogous to a natural disaster) which flows into Greece. The 'prepositional circumstantial' of the 'location/place' (Halliday \& Matthiessen, 2004, p. 262) realized by the prepositional nominal group 'in the Eastern Aegean' situates the invasion ('Wave of inflows') on the Greek-Turkish borders, advancing the sense of danger and threat in light of the traumatic past and fragile bilateral relations between the two states.

The visual representation (figure 1) complements this negative conceptualization. Immigrants are represented in the press photo as a solid, 'assimilated' (Van Leeuwen, 2008, p. 37) social entity without evident e.g. cultural differences. Moreover, in the photograph, the assimilated group is portrayed as a massive (it shows a mass of persons, not really individually distinguishable, most of them with their heads and faces covered to protect them from the sun) but static social entity probably in a Greek island hotspot. The previous conceptualization of a natural disaster ('wave') flowing into the country has now turned into a massive group statically remaining (sitting, in the picture) in Greek territory. This choice broadens the image of an extensive invasion, which is now perceived as resulting in a massive presence on Greek terrain. Additionally, in this case, no individual is looking towards the viewer. This portrayal does not permit interaction between the participants and the audience and consequently cultivates an in- vs. out-group dichotomy. More specifically, by representing the group as being 'below us' (probably also due to the framing choice of the camera angle being relatively high) ${ }^{7}$ it seems that Kathimerini 'disempower[s]' migrants and thus portrays them as inferior as well as also visually 'objectivizing' individuals, 'representing people as objects for our scrutiny' without permitting any further interrelation with the audience (Van Leeuwen, 2008, pp. 140-141). 
This is a post print version. Please refer to the published version: Serafis, D., Greco, S., Pollaroli, C. and Jermini-Martinez Soria, C. (2020). Towards an integrated argumentative approach to multimodal critical discourse analysis: Evidence from the portrayal of refugees and immigrants in Greek newspapers. Critical Discourse Studies 17(5): 545-565

The analysis of the interplay between visual and verbal modes permits us to scrutinize the construed meaning and pinpoint its potential argumentativity. Based on this first step, we will seek to unveil the inferential configuration that explains this largely implicit argumentation on the issue illustrated above. In order to reconstruct the implicit standpoint, as stated above, we will situate the multimodal configuration (headline and photo) within existing discourses and events that constitute the contextual background to the article. The implicit standpoint that we reconstruct based on our understanding of the context and the analysis of multimodal elements could be formulated as follows: 'The wave of immigrant inflows at the Greek borders must be stopped'. The argument that supports this implicit standpoint is derived from the conceptualizations construed by the (explicit) interrelation between the headline ('Waves of inflow in the Eastern Aegean') and the photograph. In order to study how argument and standpoint are connected and related to the socio-cultural context of this headline and photo, we employ the quasi-Y structure of the Argumentum Model of Topics (figure 2).

Firstly, on the procedural-inferential component of the inferential configuration, the locus from termination and setting up is employed. ${ }^{8}$ In particular, the following maxim is used: 'If $X$ is a negative and dangerous phenomenon, $X$ must be stopped'. ${ }^{9} A$ minor premise is associated with this maxim, namely 'There is a negative and dangerous phenomenon taking place at the eastern Greek borders', paving the way for the final conclusion, which is encapsulated in the following line: 'The wave of immigrant inflows at the Greek borders must be stopped'. This procedural-inferential component of the $\mathrm{Y}$ structure, as based on the locus (topos), is instantiated in a concrete case represented by the material-contextual component, i.e. the shared knowledge and values activated in the specific context necessary to justify that the minor premise associated with the maxim is well-founded. In this specific case, the material-contextual component justifies that 'There is a negative and dangerous phenomenon taking place at the eastern Greek borders': this proposition, thus, is both the first conclusion of the material-contextual component and the minor premise of the procedural, inferential component, as shown graphically in figure 2. Consequently, on the material component axis, the major material premise (endoxon) in this specific social setting could be the following: 'Waves of immigrant inflows are a negative and dangerous phenomenon'. On the same axis, the datum provided could be: 'There is a massive wave of immigrant inflows on the eastern Greek borders'. The combination of the endoxon and datum gives rise to the first conclusion 'There is a negative and dangerous phenomenon taking place on the Eastern Greek borders', which, as said, is 'needed' by the inferential-procedural component as a minor premise to arrive at the final conclusion: 'The wave of immigrant inflows on the Greek borders must be 
This is a post print version. Please refer to the published version: Serafis, D., Greco, S., Pollaroli, C. and Jermini-Martinez Soria, C. (2020). Towards an integrated argumentative approach to multimodal critical discourse analysis: Evidence from the portrayal of refugees and immigrants in Greek newspapers. Critical Discourse Studies 17(5): 545-565

stopped'. This final conclusion, as argued in our earlier discussion of methodology, coincides with the implicit standpoint that we argue is defended here.

Endoxon Waves of immigrant inflows are a negative and

dangerous phenomenon

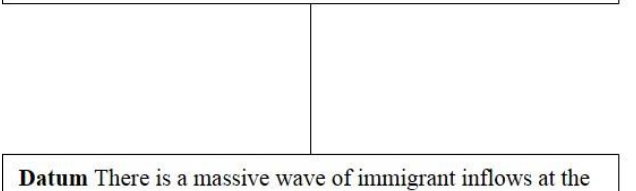

Locus from termination and setting up eastern Greek borders

Maxim If $X$ is a negative and dangerous phenomenon, $\mathrm{X}$ must be stopped

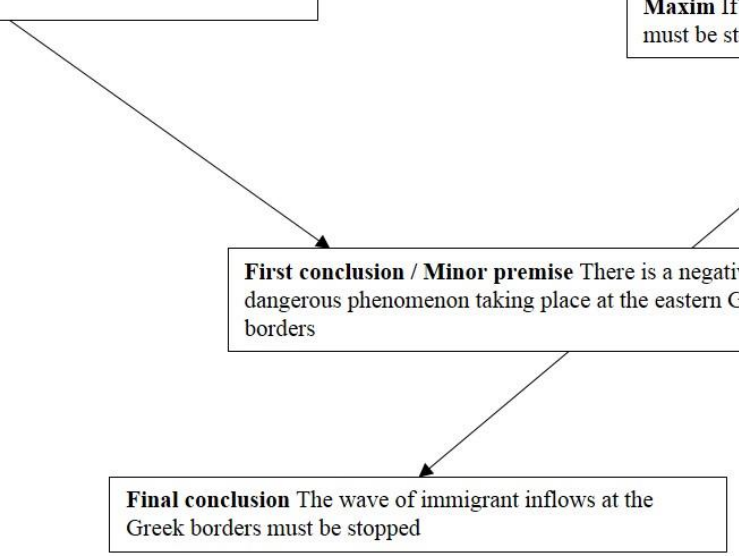

Please insert figure 2 here

Figure 2. Kathimerini, 10.07.2015 - AMT quasi-Y structure

In the second article, the newspaper Ta Nea initially reports on a topic of heated discussion in Greece in this specific period, that is the stifling situation occurring in Greece's biggest port (Piraeus), where large camps of migrants and refugees were temporarily set up. Then, the article describes the plan made by the Greek authorities (i.e. the Ministry of Migration Policy and Ministry of Shipping and Island Policy) to transfer the migrant and refugee populations from the Piraeus harbor to other, permanent hospitality units in Greece. ${ }^{10}$

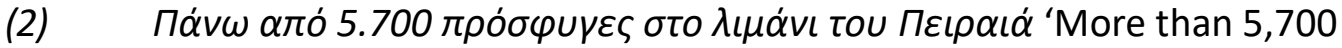
refugees at Piraeus port' (Ta Nea, 30.03.2016) 
This is a post print version. Please refer to the published version: Serafis, D., Greco, S., Pollaroli, C. and Jermini-Martinez Soria, C. (2020). Towards an integrated argumentative approach to multimodal critical discourse analysis: Evidence from the portrayal of refugees and immigrants in Greek newspapers. Critical Discourse Studies 17(5): 545-565

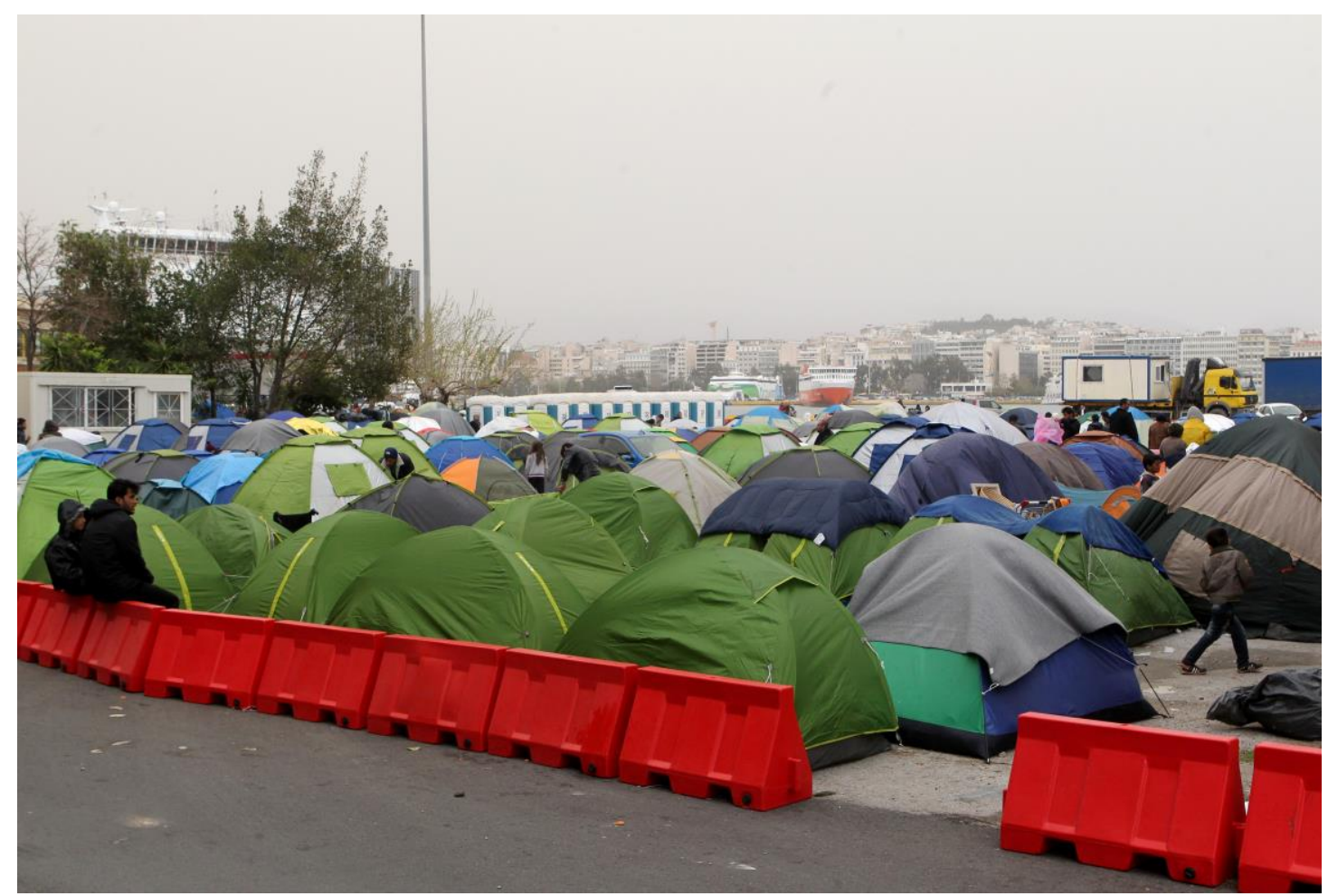

Please insert figure 3 here

Figure 3. Ta Nea, 30.03.2016. With permission: No 3497630 @ ANA-MPA/PANTELIS SAITAS)

In the headline of $\mathrm{Ta} \mathrm{Nea}$, the social groups under examination (refugees and immigrants) are explicitly represented via the nominal type $\pi \rho o ́ \sigma \varphi \cup ү \varepsilon \varsigma$ 'refugees'. In this case, the social actors being represented are, in Van Leeuwen's terms, assimilated via 'aggregation', thus via a quantification which 'treat[s] them as statistics', augmenting the sense of a massive presence of foreign populations on Greek soil. The main function of this particular mode of representation is to 'manufacture consensus opinion' (2008, p. 37); in our case around the illegal, massive and diffused presence of foreign/refugee populations in Greece. The prepositional circumstantial realized by the

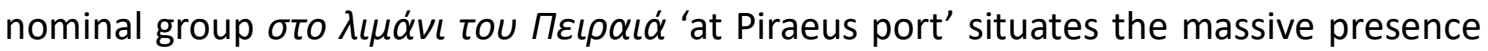
of refugees at Greece's biggest port. Background knowledge establishes the coherence of this interpretation in the specific context. In fact, the port of Piraeus was among the top-priority privatizations according to the terms and conditions of the bailout programs (MoU; Memoranda of Understanding) that different Greek governments had been implementing since May 2010. In this regard, the shipping colossus COSCO had already made successive offers to the Greek authorities and the relevant investment has been dominantly conceived as significant in the context of the recovery of the Greek economy. ${ }^{11}$ The presence of migrant camps at the harbor was perceived as 
This is a post print version. Please refer to the published version: Serafis, D., Greco, S., Pollaroli, C. and Jermini-Martinez Soria, C. (2020). Towards an integrated argumentative approach to multimodal critical discourse analysis: Evidence from the portrayal of refugees and immigrants in Greek newspapers. Critical Discourse Studies 17(5): 545-565

creating major obstacles to the buyout agreement and the company's business plan. Thus, the conceptualization of refugees and immigrant groups as dangerous invaders (see headline 1) is complemented by their conceptualization as obstacles to Greece's economic recovery.

The visual representation further loads the meaning. The refugees and immigrant groups are represented as objectivized; realized by the metonymical (visual) presence of the tents in figure 3. In addition, the crash barriers create a border that identifies and excludes the objectivized 'others' and the red color of the barriers represents a restricted area (see Kress \& Van Leeuwen, 2002) where 'others' are grouped and isolated. The few individuals visible in the image appear in a long shot, without looking towards the viewer, augmenting the social, cultural etc. distance (Van Leeuwen, 2008; see also Kress \& Van Leeuwen, 1996) and re-establishing henceforth the sense of the excluded 'other'.

In this headline, the argumentative potential may be reconstructed as a complex inferential structure, composed of two different but interconnected inferential steps that are seen as subordinative argumentation (Van Eemeren \& Snoeck Henkemans, 2017, p. 58ff). In this case, an implicit standpoint could be reconstructed as follows: 'The port of Piraeus should be evacuated', i.e. the migrants should be removed from the port (we will call this standpoint 1 ). This is supported by what is explicitly said in the headline, namely '[There are] More than 5,700 refugees at Piraeus port' (we will call this argument 1.1), which can be interpreted as an argument within the socio-cultural context from which this headline emerges. This argument, in turn, is supported by another argument, which remains unspoken in the title (but is present in other dominant discourses established at the same time by media, political etc. institutions), namely that: 'the presence of refugees at Piraeus port endangers foreign investments' (we will call this argument $1.1 .1^{12}$ ). Since, as we have explicitly mentioned, the Argumentum Model of Topics analyzes single arguments, two different $Y$ structures are necessary to analyze this subordinative argumentation (see figure 4).

As a first step of this analysis, we consider the connection between standpoint 1 and argument 1.1. On the procedural component, the locus from termination and setting up is realized in the maxim 'If $\mathrm{X}$ is an obstacle, $\mathrm{X}$ should be removed'. The minor premise associated with the maxim in this case could be reconstructed as 'There is an obstacle to Greece's economic recovery at Piraeus port'. Taken together, these two premises bring us to the final conclusion 'The port of Piraeus should be evacuated/the refugees should be moved from Piraeus port', which coincides with the implicit standpoint 1 , as reconstructed above. The material-contextual component specifies why it is true that 'There is an obstacle to Greece's economic recovery at Piraeus port', based on an endoxon that can be formulated as 'The refugees at Piraeus port are an 
This is a post print version. Please refer to the published version: Serafis, D., Greco, S., Pollaroli, C. and Jermini-Martinez Soria, C. (2020). Towards an integrated argumentative approach to multimodal critical discourse analysis: Evidence from the portrayal of refugees and immigrants in Greek newspapers. Critical Discourse Studies 17(5): 545-565

obstacle to Greece's economic recovery' and on a datum, provided in the title: 'There are more than 5,700 refugees at Piraeus port'.

Now, in this case, the endoxon that 'The refugees at Piraeus port are an obstacle to Greece's economic recovery' receives further justification from argument $1.1 .1,^{13}$ which is a subordinative argument specifically supporting the endoxon (cf. Rigotti \& Greco, 2019, pp. 233-234). As anticipated above, this subordinative argument is not present in the headline or picture, but we can infer it from the surrounding, dominant discourses, which were portraying foreign private investments as a key solution to Greece's economic recovery and refugees/migrants' presence as an obstacle in this perspective. As for the inferential configuration that connects argument 1.1.1 to (the endoxon within) argument 1.1, this is based on the locus from definition embodied by the maxim 'If $\mathrm{X}$ endangers the achievement of something positive for $\mathrm{Y}, \mathrm{X}$ is an obstacle to the recovery of Y.' The locus from definition connects a defining characteristic that describes entities of a class to a specific entity considered. In this case, it is used to make us infer that migrants are, indeed, an obstacle (to something important). The minor premise associated with the maxim is the following: 'The presence of refugees at Piraeus port endangers the achievement of something positive'. This minor premise is justified, thus becoming the first conclusion of the materialcontextual component. The major material-contextual premise (endoxon) could be the following: 'Foreign investments are a positive thing for Greece'. On the same axis, the minor premise (datum) could be: 'The presence of refugees at Piraeus port endangers foreign investments (i.e. the buyout offer from COSCO and the associated business plan for the perceived improvement of the services provided)'. 
This is a post print version. Please refer to the published version: Serafis, D., Greco, S., Pollaroli, C. and Jermini-Martinez Soria, C. (2020). Towards an integrated argumentative approach to multimodal critical discourse analysis: Evidence from the portrayal of refugees and immigrants in Greek newspapers. Critical Discourse Studies 17(5): 545-565

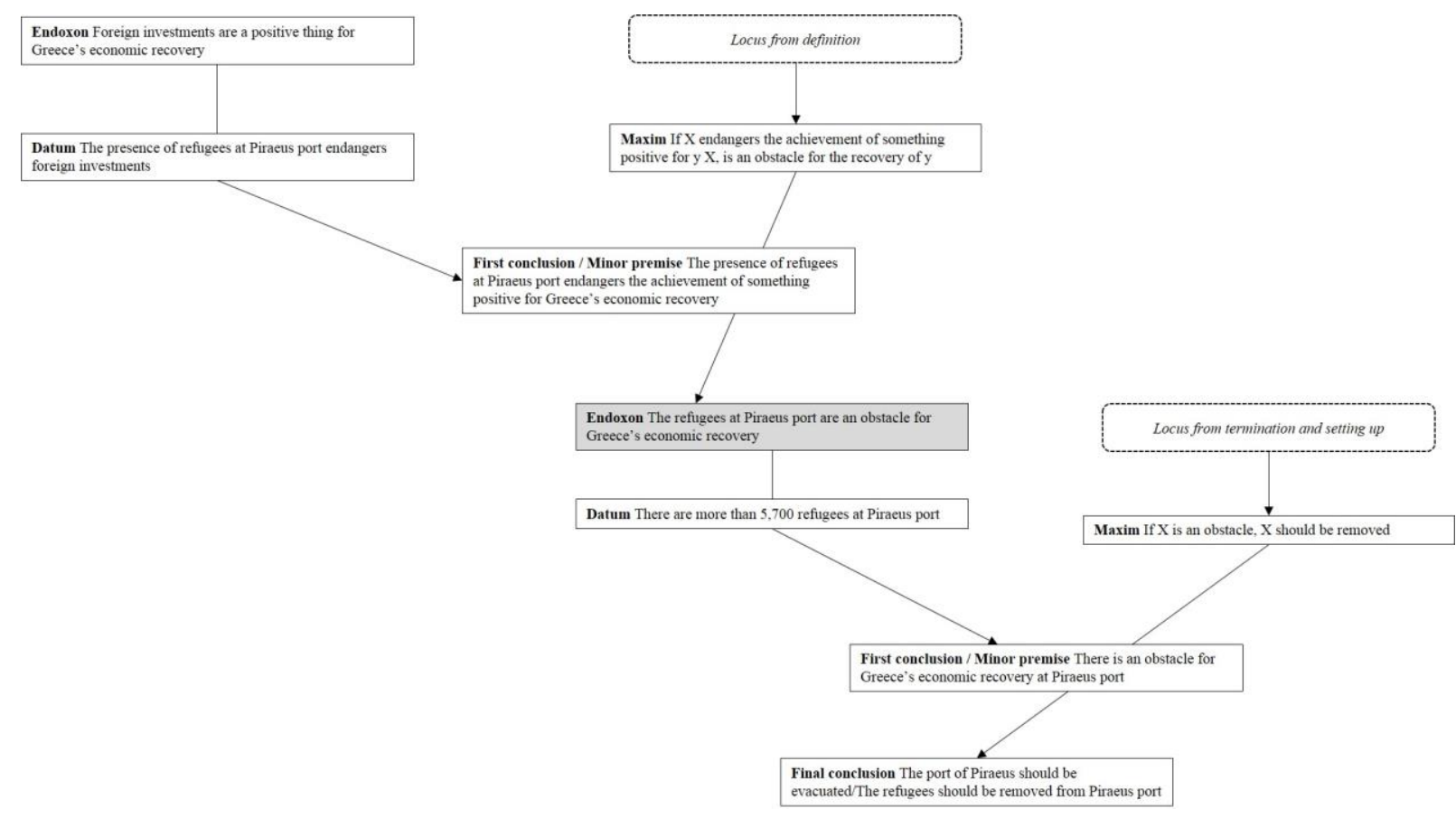

Please insert figure 4 here

Figure 4. Ta Nea, 30.03.2016 - The AMT quasi-Y structure. The final conclusion of the first quasi-Y structure corresponds to the endoxon of the second quasi-Y structure.

\section{Discussion and Conclusions}

Although our contribution is a methodological one, in terms of content, our analysis has illustrated that the examined multimodal constructions seem to embrace an already negative conceptualization of migrant populations in the Greek/EU context, suggesting argumentative inferences. This negative conceptualization has been extensively analyzed in recent studies concerning the 'refugee crisis' (see e.g. Krżyzanowski, Triandafyllidou \& Wodak, 2018). More specifically, in the two examples, migrants and refugees are portrayed first and foremost as a natural disaster ('wave') (see also e.g. Musolff, 2015) flowing into the country's terrain (Kathimerini 10.07.2015). Moreover, the massive presence of refugees occurs in the biggest Greek port ('Piraeus') endangering Greece's economic recovery after a long period of financial crisis ( $\mathrm{Ta} N \mathrm{Nea}$ 30.03.2016). As we show in both cases, the standpoints implicitly emerging from the discursive constructions mentioned above underpin the perceived necessity to prevent the migratory phenomenon. In this interpretation, the combination of the headline and photo is seen as an argument (or a complex argumentation) that supports those implicit standpoints. It is worth mentioning that in the present case, the two newspapers seem to converge on these negative depictions/standpoints, de facto 
This is a post print version. Please refer to the published version: Serafis, D., Greco, S., Pollaroli, C. and Jermini-Martinez Soria, C. (2020). Towards an integrated argumentative approach to multimodal critical discourse analysis: Evidence from the portrayal of refugees and immigrants in Greek newspapers. Critical Discourse Studies 17(5): 545-565

amplifying (racist, xenophobic) conceptualizations although they have clearly different (ideological/political) backgrounds. We underline here that these observations could by no means be considered as empirical observations about the ways in which migrants and refugees are portrayed in Greek media. A more extensive data analysis would be necessary to illustrate this tendency, confirmed by other critical discourse studies; the lack of extensive empirical findings remains one of the main limitations of a methodologically oriented paper such as the present one. The main aim of this paper was not to unveil recurrent patterns in terms of content, but rather to show that the proposed methodological synergy can sharpen multimodal critical discourse studies and suggest a way of reconstructing the argumentative potential of news reporting.

In terms of methodology, several findings have emerged from our study. Firstly, our approach has shown that the multimodal constructions of meaning which appear in the examined newspapers shape coherent argumentative discourses. The analysis treated the headline and image separately for clarity, underlining nevertheless that the visual element adds further meaning to the headline and vice versa. It is in the combination of visual and verbal elements that recent studies, 'acknowledg[ing] the multimodal character of communication [maintain that] argumentation as an activity finds its place' (Tseronis, 2018, p. 52). Then, it was in the reconstruction of the argument-to-standpoint process that the information extracted from each of the aforementioned semiotic modes could be fully combined, providing us with detailed insights regarding the argumentativity of multimodal configurations. This particular finding has great significance since we are dealing here with linguistic/semiotic packaging that does not belong to an explicitly argumentative genre. So, the analytical integration we propose may be employed by critical discourse analysts in order to study how even seemingly non-argumentative structures of (multimodal) discourses sustain an argumentation dynamic (Amossy, 2010). This dynamic may be further advanced within an argumentative discussion between different social actors, running the risk of implicitly favoring the enforcement of social problems and inequalities (such as racism in this case).

Conversely, from a viewpoint of Argumentation theory, this kind of study may deepen recent debates, which focus on the emergence of arguments in non-explicitly argumentative genres, such as e.g. narratives (see Olmos 2017). Of course, the reconstruction of argumentation within texts that are only indirectly argumentative and, therefore, in which the standpoint needs to be reconstructed from contextual information, implies some risk of over-interpretation and needs to be justified thoroughly; this remains an open question for analysts who address the argumentative potential of news stories. Even so, addressing this type of argumentation (in e.g. narratives, and other genres) is important to highlight how inferences might be 
This is a post print version. Please refer to the published version: Serafis, D., Greco, S., Pollaroli, C. and Jermini-Martinez Soria, C. (2020). Towards an integrated argumentative approach to multimodal critical discourse analysis: Evidence from the portrayal of refugees and immigrants in Greek newspapers. Critical Discourse Studies 17(5): 545-565

triggered or suggested even just by the choice of certain specific words (Greco Morasso 2012) or images.

Secondly, using tools borrowed from the armory of multimodality (Kress \& Van Leeuwen, 1996; Van Leeuwen, 2008), widely exploited in multimodal argumentation, enabled us to scrutinize the construction of meaning underlying the argumentativity of print media discourse that otherwise would remain obscure (Amossy, 2009a, 2009b). Then, the integration of the Argumentum Model of Topics (AMT) (Rigotti \& Greco, 2019) tracked the standpoint-argument connection that can be reasonably inferred in the multimodal configurations of the discourses under examination, casting light on the precise dynamics through which certain combinations of headlines and images support argumentative discourses.

Thirdly, as we stated, our approach aimed to establish a discussion with the Discourse-Historical Approach (DHA), sharpening in this sense the dialogue between CDA approaches that incorporate argumentation theory (see Reisigl \& Wodak, 2001; Boukala, 2019). We show that the integration of the Argumentum Model of Topics (AMT) with Multimodal Critical Discourse Analysis (MCDA) follows the same conceptual lines as the discourse-historical approach to critical discourse studies, and includes the same notions which emanate from the Aristotelian tradition (i.e. topos, endoxon). Specifically, both approaches primarily proceed to a systematic and rigorous analysis of linguistic and other semiotic means (e.g. press photos) in order to track obscure constructions of meaning on which argumentation is premised. Then, an argumentative reconstruction traces the interconnection between the different premises (material-contextual and procedural-inferential) on which the argumentstandpoint relationship is structured, allowing the inferential configuration that lies behind the argument-standpoint relationship to become explicit (Rigotti \& Greco, 2019)..$^{14}$

More specifically, as recent developments within the discourse-historical approach to CDA argue, topos/topoi and endoxon interrelate and, in particular, topos/topoi (or, to use the AMT equivalent terminology, locus/loci) challenge endoxical (shared) knowledge in the development of the argumentative syllogism (see Boukala, 2019, Chapter 4). However, in our view, the passage that unifies topical and endoxical premises, moving us towards the expressed standpoint, remains unclear in a DHA/CDA perspective from an inferential viewpoint. The Argumentum Model of Topics may heal this inconsistency since, as we show, it precisely captures in its quasi-Y structure the interaction of endoxical (material-contextual component) and topical (proceduralinferential component) syllogisms, highlighting how the final conclusion (corresponding to the standpoint) is reached. Interestingly, in our analysis (see figure 4) we have seen a case in which inference based on a topos/locus does not necessarily challenge an 
This is a post print version. Please refer to the published version: Serafis, D., Greco, S., Pollaroli, C. and Jermini-Martinez Soria, C. (2020). Towards an integrated argumentative approach to multimodal critical discourse analysis: Evidence from the portrayal of refugees and immigrants in Greek newspapers. Critical Discourse Studies 17(5): 545-565

endoxon but reinforces it, giving it further backing. This reinforcing connection between topos and endoxon deserves further investigation, again, on a broader empirical basis. In other words, the Argumentum Model of Topics shows the two-way structure of the inferential configuration, leading us smoothly to the claimed standpoint. In this sense, the Argumentum Model of Topics may deepen the analytical capacity of CDA argumentative-oriented approaches above all in cases where much of the argumentative potential and dynamic remain implicit, as in the case under examination here. It might also represent a methodological grid for reconstructing implicit premises, allowing endoxical knowledge that is widespread in society to be grounded, unveiling how it is used within specific inferential and discursive moves.

Moreover, apart from the aforementioned contribution, we should also underline here that, at the theoretical level, the distinction between topos/locus and maxims that the Argumentum Model of Topics makes in the procedural-inferential component may also have an added analytic advantage. As we have already mentioned (see footnote 8 ), this choice limits the topoi to a reasonable number, while permitting us to discover virtually infinite maxims, working as major premises related to a topos/locus, in the analysis of different texts. Therefore, analysts can avoid constant ad hoc constructions of topoi (to which some critical discourse analysts may be subjected)..$^{15}$

Overall, the approach developed in this paper has attempted to illustrate detailed and integrated tools for a step-by-step scrutiny of the multimodal micro-level of print media discourse with a focus on the 'refugee crisis' in Greece. It has done so, in constant interrelation with the (racist, xenophobic) macro-level views circulating in the Greek/EU context. Our study, situated in this bi-focal perspective, has attempted to sketch a rigorous methodological approach to multimodal critical discourse studies with a particular focus on Greece, which is the epicenter of multiple crises (see Wodak \& Angouri, 2014; Hatzidaki \& Goutsos, 2017). In this vein, we have attempted to enrich the agenda of emancipation and the toolkit of CDA perspectives.

\section{Acknowledgments}

We would like to thank the Athens News Agency - Macedonian Press Agency (ANA-MPA), Greece, for kindly permitting us to reproduce the press photographs that appear in the newspapers Kathimerini and Ta Nea, for the purposes of this study. We are also grateful to Judy Nagle who kindly checked the English language. Dimitris Serafis would like to thank the Sophie Afenduli Foundation for funding the project "Discursive representations, emotive constructions and (new) endoxa of argumentation: A critical study of media institutions discourses during the migratory crisis in Greece and Italy". Sara Greco and Chiara Jermini-Martinez Soria would like to thank the Swiss National Science Foundation for financing the project RefraMe ("The 
This is a post print version. Please refer to the published version: Serafis, D., Greco, S., Pollaroli, C. and Jermini-Martinez Soria, C. (2020). Towards an integrated argumentative approach to multimodal critical discourse analysis: Evidence from the portrayal of refugees and immigrants in Greek newspapers. Critical Discourse Studies 17(5): 545-565

inferential dynamics of reframing within dispute mediators' argumentation", SNF 10001C_17004/1, 2017-2020; applicant: Sara Greco, collaborator: Chiara Jermini-Martinez Soria). Although the data analyzed in this paper are different, the current development of the Argumentum Model of Topics (AMT) is tightly related to this project. Finally, we are indebted to our colleagues at IALS-USI and to two anonymous reviewers for their constructive observations on a previous version of this paper.

\section{Notes on the contributors}

Dimitris Serafis is a post-doctoral researcher affiliated at the Institute of Argumentation, Linguistics and Semiotics, Faculty of Communication Sciences, USI - Università della Svizzera italiana. He is a fellow of the Sophie Afenduli Foundation (Lausanne, Switzerland). His research interests lie at the intersection of Critical Discourse Analysis and Argumentation/Rhetoric under the lens of a Systemic Functional (and Multimodal) analytical perspective, with his current focus being on media discourse and media construction, migration and racism, protest discourse and the construction of collective identity/ies, and communication in periods of crisis.

Sara Greco (PhD 2009) is Senior Assistant Professor of argumentation at USI - Università della Svizzera italiana, where she leads a research team working on argumentation and teaches argumentation and verbal communication. Her main research area is argumentation in conflict resolution (see the monograph Argumentation in dispute mediation: A reasonable way to handle conflict, John Benjamins 2011), both at the interpersonal level and at a broader societal level. She has also been working and argumentation in delicate situations such as adultchildren interactions in family and educational settings, considering how discussions spaces are created and how arguments are inferentially constructed (see E. Rigotti \& S. Greco, Inference in argumentation: A topics-based approach to argument schemes, Springer 2019). Finally, she has developed research in the area of inner argumentation, in particular in the case of international migrants' decision-making processes. In all these areas, Greco is directing and participating in research projects, often in collaboration with colleagues from other disciplines. Greco has extensive expertise in the empirical analysis of spoken and written argumentation, based on methodologies from argumentation, Discourse Analysis and linguistics.

Chiara Pollaroli is a Post-doc fellow at the Institute of Argumentation Linguistics and Semiotics at Università della Svizzera italiana. She teaches Multimodal Rhetoric at the Master level and Discourse Analysis at the Bachelor level. She has conducted and published research on metaphor and argumentation, on multimodal argumentation, and on advertising.

Chiara Jermini-Martinez Soria is a PhD student and teaching assistant at USI - Università della Svizzera italiana, Faculty of Communication Sciences, Institute of Argumentation, Linguistics and Semiotics. She is currently working on the SNSF funded research project "The inferential dynamics of reframing within dispute mediator's argumentation". Her research 
This is a post print version. Please refer to the published version: Serafis, D., Greco, S., Pollaroli, C. and Jermini-Martinez Soria, C. (2020). Towards an integrated argumentative approach to multimodal critical discourse analysis: Evidence from the portrayal of refugees and immigrants in Greek newspapers. Critical Discourse Studies 17(5): 545-565

interests include dispute mediation and conflict resolution, discourse analysis, pragmatics and applied linguistics.

\section{References}

Amossy, R. (2005). The argumentative dimension of discourse. In F. H. Van Eemeren \& P. Houtlosser (Eds.), Practices of Argumentation (pp. 87-98). Amsterdam: John Benjamins.

Amossy, R. (2009a). The New Rhetoric's inheritance. Argumentation and discourse analysis. Argumentation, 23, 313-324.

Amossy, R. (2009b). Argumentation in discourse: A socio-discursive approach to arguments. Informal Logic, 29(3), 252-267.

Amossy, R. (2010). L'argumentation dans le discours [Argumentation in discourse] (3rd ed.). Paris: A. Colin.

Angouri, J. \& Wodak, R. (2014). 'They became big in the shadow of crisis': The Greek success story and the rise of the far right. Discourse \& Society, 25(4), 540-565.

Atkin, A. \& Richardson, J. E. (2007). Arguing about Muslims: (Un)reasonable argumentation in letters to the editor. Text \& Talk, 27(1), 1-25.

Baker, P., Gabrielatos, C., KhosraviNik, M., Krzyżanowski, M., McEnery, T. \& Wodak, R. (2008). A useful methodological synergy? Combining critical discourse analysis and corpus linguistics to examine discourses of refugees and asylum seekers in the UK press. Discourse \& Society, 19(3), 273-306.

Bednarek, M. \& Caple, H. (2012a). 'Value added': Language, image and news values. Discourse, Context \& Media, 1(2-3), 103-113.

Bednarek, M. \& Caple, H. (2012b). News discourse. London and New York, NY: Continuum.

Bell, A. (1991). The Language of news media. Oxford: Blackwell.

Boukala, S. (2016). Rethinking topos in the discourse historical approach: Endoxon seeking and argumentation in Greek media discourses on 'Islamist terrorism'. Discourse Studies, 18(3), 249-268.

Boukala, S. (2019). European identity and the representation of Islam in the mainstream press: Argumentation and media discourse. London: Palgrave Macmillan.

Boukala, S. \& Dimitrakopoulou, D. (2018). Absurdity and the 'Blame Game' within the Schengen area: Analyzing Greek (social) media discourses on the refugee crisis. Journal of Immigrant \& Refugee Studies, 16(1-2), 179-197.

Breazu, P. \& Machin, D. (2018). A critical multimodal analysis of the Romanian press coverage of camp evictions and deportations of the Roma migrants from France. Discourse \& Communication, 12(4), 339-356. 
This is a post print version. Please refer to the published version: Serafis, D., Greco, S., Pollaroli, C. and Jermini-Martinez Soria, C. (2020). Towards an integrated argumentative approach to multimodal critical discourse analysis: Evidence from the portrayal of refugees and immigrants in Greek newspapers. Critical Discourse Studies 17(5): 545-565

Fairclough, N. (2003). Analysing discourse: textual analysis for social research. London: Routledge.

Fairclough I. \& Fairclough, N. (2012). Political discourse analysis: A method for advanced students. London: Routledge.

Feteris, E. T., Groarke, L., \& Plug, H. J. (2011). Strategic maneuvering with visual arguments in political cartoons: A pragma-dialectic analysis of the use of the topoi that are based on common cultural heritage. In E. T. Feteris, B. Garssen, \& A. F. Snoeck Henkemans (Eds.), Keeping in touch with pragma-dialectics: In honor of Frans H. Van Eemeren (pp. 59-74). Amsterdam: John Benjamins.

Flowerdew, J. \& Richardson, J. (2018). The Routledge handbook of critical discourse studies. London: Taylor \& Francis.

Forceville, C. (1996). Pictorial metaphor in advertising. London: Routledge.

Gabrielatos, C. \& Baker, P. (2008). Fleeing, sneaking, flooding: A corpus analysis of discursive constructions of refugees and asylum seekers in the UK Press, 19962005. Journal of English Linguistics, 36(1), 5-38.

Greco Morasso, S. (2012). Contextual frames and their argumentative implications: A case-study in media argumentation. Discourse Studies, 14(2), 197-216.

Greco Morasso, S. \& Morasso, C. (2014). Argumentation from expert opinion in science journalism: The case of Eureka's Fight Club. In S. Oswald \& T. Herman (Eds.), Rhétorique et Cognition (pp. 185-213). Bern: Peter Lang.

Greco, S., Perret-Clermont, A.N., lannaccone, A., Rocci, A., Convertini, J. \& Schär, R. (2018). The analysis of implicit premises within children's argumentative inferences. Informal Logic, 38(4), 438-470.

Groarke, L. (1996). Logic, art and argument. Informal Logic, 18, 105-129.

Halliday, M. A. K. (1978). Language as social semiotic: The social interpretation of language and meaning. London: Arnold.

Halliday, M. A. K. \& Matthiessen, Ch. M. I. M. (2004). An Introduction to functional grammar (3rd ed.). London: Arnold.

Hart, C. (2014). Discourse, grammar and ideology: Functional and cognitive perspectives. London: Bloomsbury.

Hatzidaki, O. \& Goutsos, D. (Eds.). (2017). Greece in crisis: Combining critical discourse and corpus linguistics perspectives. Amsterdam: John Benjamins.

Herman, T. \& Serafis, D. (forthcoming). Emotions, argumentation and argumentativity: Insights from an analysis of newspapers headlines in the context of the Greek crisis. Informal Logic.

KhosraviNik, M. (2009). The representation of refugees, asylum seekers and immigrants in British newspapers during the Balkan conflict (1999) and the British general election (2005). Discourse \& Society, 20(4), 477-498. 
This is a post print version. Please refer to the published version: Serafis, D., Greco, S., Pollaroli, C. and Jermini-Martinez Soria, C. (2020). Towards an integrated argumentative approach to multimodal critical discourse analysis: Evidence from the portrayal of refugees and immigrants in Greek newspapers. Critical Discourse Studies 17(5): 545-565

KhosraviNik, M. (2010). The representation of refugees, asylum seekers and immigrants in British newspapers: A critical discourse analysis. Journal of Language and Politics, 9(1), 1-28.

Krżyzanowski, M. \& Wodak, R. (2008). The politics of exclusion. Debating migration in Austria. New Brunswick, NJ: Transaction Publishers.

Krżyzanowski, M., Triandafyllidou, A. \& Wodak, R. (Eds.). (2018). The mediatisation and politicisation of the 'refugee crisis' in Europe [Special issue]. Journal of Immigrant \& Refugee Studies, 16(1-2).

Kjeldsen, J. E. (Ed.). (2015). Visual and Multimodal Argumentation [Special Issue]. Argumentation, 29(2).

Kjeldsen, J. E. (2017). The rhetorical and argumentative potentials of press photography. In A. Tseronis \& C. Forceville (Eds.), Multimodal argumentation and rhetoric in media genres (pp. 51-80). Amsterdam/Philadelphia: John Benjamins.

Kress, G. (2010). Multimodality: A social-semiotic approach to contemporary communication. London: Routledge.

Kress, G. \& Van Leeuwen, T. (1996). Reading images: The grammar of visual design. Routledge: London.

Kress, G. \& Van Leeuwen, T. (1998). Front pages: (The critical) analysis of newspaper layout. In A. Bell \& P. Garrett (Eds.), Approaches to media discourse (pp. 186219). Oxford: Blackwell.

Kress, G. \& Van Leeuwen, T. (2002). Colour as a semiotic mode: Notes for a grammar of colour. Visual Communication, 1(3), 343-368.

Ledin, P. \& Machin, D. (2018). Doing visual analysis: From theory to practice. Thousand Oaks, CA: Sage.

Machin, D. \& Mayr, A. (2012). How to do critical discourse analysis: A multimodal introduction. Thousand Oaks, CA: Sage.

Martin, G. (2015). Stop the boats! Moral panic in Australia over asylum seekers. Continuum, 29(3), 304-322.

Martínez-Lirola, M. (2017). Analysing visual dysphemisms in news items on the arrival of sub-saharan immigrants to Spain in small boats: Visual strategies of pity, fear and compassion. Palavra Clave, 20(2), 411-443.

Musolff, A. (2015). Dehumanizing metaphors in UK immigrant debates in press and online media. Journal of Language Aggression and Conflict, 3(1), 41-56.

Olmos, P. (Ed.) (2017). Narration as argument. Cham: Springer.

Palmieri, R. (2014). Corporate argumentation in takeover bids. Amsterdam/Philadelphia: John Benjamins.

Perelman, Ch. \& Olbrechts-Tyteca, L. (1969 [1958]). The new rhetoric: A treatise on argumentation. Notre Dame: Notre Dame University Press. 
This is a post print version. Please refer to the published version: Serafis, D., Greco, S., Pollaroli, C. and Jermini-Martinez Soria, C. (2020). Towards an integrated argumentative approach to multimodal critical discourse analysis: Evidence from the portrayal of refugees and immigrants in Greek newspapers. Critical Discourse Studies 17(5): 545-565

Pollaroli, C. (2016). T(r)opical patterns in advertising. The argumentative relevance of multimodal metaphor in print advertisements. PhD dissertation, Università della Svizzera italiana.

Pollaroli, C. \& Rocci, A. (2015). The argumentative relevance of pictorial and multimodal metaphor in advertising. Journal of Argumentation in Context, 4(2), 158-199.

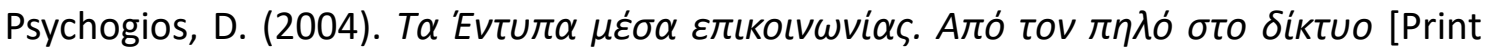
media. From the clay to the network]. Athens: Kastaniotis.

Reisigl, M. \& Wodak, R. (2001). Discourse and discrimination: Rhetorics of racism and antisemitism. London: Routledge.

Reisigl, M. \& Wodak, R. (2016). The discourse-historical approach (DHA). In R. Wodak, \& M. Meyer (Eds.), Methods of critical discourse studies (3rd ed.) (pp. 23-61). London: Sage.

Richardson, J. E. (2004). (Mis)Representing Islam: The racism and rhetoric of British broadsheet newspapers. Amsterdam/Philadelphia: John Benjamins.

Richardson, J. E. (2007). Analysing newspapers: An approach from critical discourse analysis. New York, NY: Palgrave Macmillan.

Richardson, J. E. (2008). 'Our England': Discourses of 'race' and class in party election leaflets. Social Semiotics, 18(3), 321-336.

Richardson, J. E. \& Wodak, R. (2009). The impact of visual racism: Visual arguments in political leaflets of Austrian and British far-right parties. Controversia, 6(2), 45-77.

Rigotti, E. \& Greco Morasso, S. (2010). Comparing the argumentum model of topics to other contemporary approaches to argument schemes: The procedural and material components. Argumentation, 24, 489-512.

Rigotti, E. \& Greco, S. (2019). Inference in argumentation: A topics-based approach to argument schemes. Cham: Springer.

Rocci, A. \& Pollaroli, C. (Eds.). (2018). Multimodality in argumentation [Special Issue]. Semiotica, 220.

Serafis, D. \& Herman, T. (2018). Media discourse and pathos: Sketching a critical and integrationist approach - Greek and French headlines before the Greek referendum of 2015. Social Semiotics, 28(2), 184-200.

Tseronis, A. 2015. Multimodal argumentation in news magazine covers: A case study of front covers putting Greece on the spot of the European economic crisis. Discourse, Context and Media, 7, 18-27.

Tseronis, A. 2017. Analysing multimodal argumentation within the pragma-dialectical framework: Strategic manoeuvring in the front covers of The Economist. In F. H. Van Eemeren \& W. Peng (Eds.), Contextualizing pragma-dialectics (pp. 335-359). Amsterdam: John Benjamins. 
This is a post print version. Please refer to the published version: Serafis, D., Greco, S., Pollaroli, C. and Jermini-Martinez Soria, C. (2020). Towards an integrated argumentative approach to multimodal critical discourse analysis: Evidence from the portrayal of refugees and immigrants in Greek newspapers. Critical Discourse Studies 17(5): 545-565

Tseronis, A. 2018. Multimodal argumentation: Beyond the verbal/visual divide. Semiotica, 220, 41-67.

Tseronis, A. \& Forceville, C. (Eds.). (2017). Multimodal argumentation and rhetoric in media genres. Amsterdam/Philadelphia: John Benjamins.

Van Dijk, T. A. (1988). News as discourse. Hillsdale, NJ: Lawrence Erlbaum.

Van Dijk, T. A. (1991a). Racism and the press. London: Routledge.

Van Dijk, T. A. (1991b). The interdisciplinary study of news as discourse. In K. BruehnJensen, \& N. Jankowski (Eds.), Handbook of qualitative methods in mass communication research (pp. 108-120). London: Routledge.

Van Dijk, T. A. (2008). Discourse and power. New York, NY: Palgrave Macmillan.

Van Eemeren, F. H., \& Grootendorst, R. (2004). A systematic theory of argumentation: The pragma-dialectical approach. Cambridge: Cambridge University Press.

Van Eemeren, F. H, \& Snoeck Henkemans, A. F. (2017). Argumentation: Analysis and evaluation (2nd ed.). New York, NY: Routledge.

Van Leeuwen, T. (2005). Three models of interdisciplinarity. In R. Wodak \& P. Chilton (Eds.), A new agenda in (critical) discourse analysis (pp. 3-18). Amsterdam/Philadelphia: John Benjamins Publishing Company.

Van Leeuwen, T. (2008). Discourse and practice: New tools for critical discourse analysis. New York, NY: Oxford University Press.

Wodak, R. (2001). The discourse historical approach. In R. Wodak \& M. Meyer (Eds.), Methods of critical discourse analysis (pp. 63-95). London: Sage.

Wodak, R. (2015). The politics of fear: What right-wing populist discourses mean. London: Sage.

Wodak, R. \& Angouri, J. (Eds.). (2014). From Grexit to Grecovery: Euro/crisis discourses [Special Issue]. Discourse \& Society 25(4).

Žagar, I. (2010). Topoi in Critical Discourse Analysis. Lodz Papers in Pragmatics 6(1), 327.

Zampa, M. (2017). Argumentation in the newsroom. Amsterdam/Philadelphia: John Benjamins.

1 For example, the discourse in late 2012 that revolved around Greece's expulsion from the EU, labelled as 'Grexit' (Angouri \& Wodak, 2014: 541).

2 A synergy of Hallidayan views and cognitive perspectives (see metaphor analysis), although favored in recent critical discourse studies (Hart, 2014), lies beyond the scope of this article.

3 As Rigotti \& Greco (2019, p. xii-xiii) argue, it is possible to see standpoint and conclusion as coinciding from a perspective of inference: "In this sense, as we believe, the two terms - standpoint and conclusion-are not incompatible, but represent two different directions of reading of the same phenomenon: When a standpoint is defended by an argument, we may say that it is the conclusion of that argument (the conclusion, however, being external to the argument itself). This is possible because inference is a connection or transfer of acceptability, so even though standpoint/conclusion 
This is a post print version. Please refer to the published version: Serafis, D., Greco, S., Pollaroli, C. and Jermini-Martinez Soria, C. (2020). Towards an integrated argumentative approach to multimodal critical discourse analysis: Evidence from the portrayal of refugees and immigrants in Greek newspapers. Critical Discourse Studies 17(5): 545-565

and argument are separated as theoretical objects, they remain connected in the perspective of inference".

4 See though e.g. Pollaroli \& Rocci (2015) where the AMT has been applied to the argumentative analysis of multimodal discourse.

5 Other discursive strategies include: (a) 'nomination strategies' which show how the social actors are portrayed in a text (realized by e.g. metaphors), (b) 'predication strategies' by which negative or positive characteristics are attributed to participants, (c) 'perspectivation strategies' which reveal the speaker's 'point of view' and his/her 'involvement or distance' in a specific discourse and (d) 'intensification or mitigation strategies' (see Reisigl \& Wodak, 2016 p. 33 see also Reisigl \& Wodak, 2001, pp. 44-84).

6 The article can be found at: http://www.kathimerini.gr/822961/article/epikairothta/ellada/kymaeisrown-sto-anatoliko-aigaio (last accessed: 10.06.2019), giving us also a general impression of how the original multimodal text appears online.

7 In respect of this framing choice, we must underline the possibility that this has resulted from the fact that the photographer may have wanted to capture as many migrants as possible in the photo and consequently he/she had to stand on higher ground than them in order to achieve this. We are grateful to one of our anonymous reviewers for his/her comments on this possible interpretation.

8 The metaphor 'Wave of inflows' hints at the presence of a generic schema between migrant inflows and potentially dangerous natural phenomena (big waves, in this case) and activates an inference that these phenomena should be stopped, but the reference to natural phenomena in speech about immigration is so lexicalized that the inferential potential of metaphor is lowered (cf. Pollaroli, 2016). Thus, we think that the prominent inferential principle (topos/locus) activated here is that of termination and setting up, because both the headline and the photo push the emergency to the forefront, inviting action against this emergency in order to stop it. The metaphor, which-as already mentioned-is a widely used dehumanizing metaphor employed to describe migrants (see also the discussion in Martin, 2015, p. 314), is not as foregrounded as the call for action to stop a negative phenomenon.

9 Within the discourse-historical approach, Wodak (2015, p. 53) distinguishes between topoi and principles. For example, the topos from opposites is associated with the following principle: 'if the contrary of a predicate belongs to the contrary of a subject, then this predicate belongs to this subject' (ibid.; this is a topos taken from Aristotle). The principles are labelled as 'maxims' in the Argumentum Model of Topics, following a tradition initiated by Boethius and pursued throughout and after medieval studies on logic and argumentation (Rigotti \& Greco, 2019). There are at least two theoretical advantages of a clear-cut distinction between locus (topos) and maxims. First, the locus (topos) is the source of an argument, while the maxim is an implicit premise that works within the argument itself, i.e. it is a major premise in the argumentative inference. Second, the locusmaxim relation is not bijective: different maxims correspond to one and the same locus (topos). This allows the list of topoi to remain within a reasonable number, while allowing for as many maxims as the analysts discover during the analysis of real texts.

10 The article can be found at: https://www.tanea.gr/2016/03/30/greece/panw-apo-5-700-prosfygessto-limani-toy-peiraia/ (last accessed: 10.06.2019).

11 With respect to this issue, it is worth mentioning that the privatization agreement relating to the Piraeus port was signed by the left-wing Greek government (SYRIZA/European Left). As the leading party of the opposition during 2012-2014, SYRIZA had raised serious objections against programs of private investment implemented by previous Greek governments. However, upon signing the third MoU in summer 2015 SYRIZA's government was committed to a substantial privatization strategy/program, thus, loading discourses regarding privatizations with a positive meaning, and making them dominant in the Greek public sphere. See e.g. https://www.news247.gr/oikonomia/stin-cosco-to-67-toy-olp-epesan-oi-ypografes-tissymfonias.6419714.html and https://www.protothema.gr/economy/article/568170/proti-fora-polisiellinikou-limaniou/ 
This is a post print version. Please refer to the published version: Serafis, D., Greco, S., Pollaroli, C. and Jermini-Martinez Soria, C. (2020). Towards an integrated argumentative approach to multimodal critical discourse analysis: Evidence from the portrayal of refugees and immigrants in Greek newspapers. Critical Discourse Studies 17(5): 545-565

12 This numeration is adopted by the pragma-dialectical representation of complex argumentation (Van Eemeren \& Snoeck Henkemans, 2017).

13 Notably, in this case, the final conclusion and the endoxon coincide (i.e. 'The refugees at Piraeus port are an obstacle to Greece's economic recovery') because argument 1.1 .1 supports the endoxical premise.

14 For a detailed account of the complementarity between an argumentative reconstruction of standpoint and argument following the principles of Pragma-Dialectics and a reconstruction of the inferential path that links an argument and a standpoint following the Argumentum Model of Topics, see also Palmieri (2014, pp. 30-42).

15 A view that has been heavily criticized by some argumentation scholars (see Žagar, 2010). 